\title{
Structures of Extraterrestrial Minerals Revealed by EBSD
}

\author{
M. Zolensky,* and T. Mikouchi**
}

*ARES, mail code KT, NASA Johnson Space Center, Houston, TX 77058, USA

** Earth and Planetary Science, University of Tokyo, Bunkyo-ku, Tokyo 113-0033, Japan

Introduction: Our groups at the Johnson Space Center and the University of Tokyo have been using electron back-scattered diffraction (EBSD) to reveal the crystal structures of extraterrestrial minerals for years. Even though we also routinely use transmission electron microscopy, synchrotron X-ray diffraction (SXRD), and conventional electron diffraction, we find that EBSD is the most powerful technique for crystal structure elucidation in many instances. In this abstract we describe a few of the cases where we have found EBSD to provide crucial, unique information.

Asteroid 2008TC3 -Almahata Sitta: The Almahata Sitta meteorite (Alma) is the first example of a recovered asteroidal sample that fell to earth after detection while still in solar orbit (asteroid 2008TC3), and thus is critical to understanding the relationship between meteorites and their asteroidal parent bodies [1\&2]. Alma is an anomalous polymict ureilite, and the structures of the low-calcium pyroxenes have been particularly instructive.

The pyroxene crystal structure gives important information on thermal history when coupled with chemical composition. Thus we employed EBSD to study the crystallography of Alma pyroxenes. Although the Ca contents of these low-Ca pyroxenes are as low as $\mathrm{Wo}_{2}$, the obtained Kikuchi bands show that all Alma low-Ca pyroxenes have the pigeonite $(P 21 / c)$ crystal. This is consistent with the observation that (100) twinning is common in these low-Ca pyroxenes. Alma pigeonites in the same pyroxene areas show generally similar orientation as suggested by optical microscopy. The Kikuchi bands from augite in Alma can be indexed by the $C 2 / c$ augite structure, but it is usually difficult to distinguish between the $P 21 / c$ and $C 2 / c$ pyroxene structures on EBSD patterns. The absence of orthopyroxene $(\mathrm{Pbca})$ in Alma indicates that the pyroxene equilibration temperature was high, probably higher than $1300^{\circ} \mathrm{C}[3 \& 4]$.

Dmitryivanovite: The empirical formula for dmitryivanovite is $\mathrm{Ca}_{1.000}\left(\mathrm{Al}_{1.993} \mathrm{Si}_{0.003} \mathrm{Ti}_{0.002}\right)_{1.998} \mathrm{O}_{4}$ which is close to the theoretical value $\mathrm{CaAl}_{2} \mathrm{O}_{4}$ [5\&6]. Our attempts to obtain diffraction data from this phase by SXRD failed, but we successfully analyzed several different areas of $\mathrm{CaAl}_{2} \mathrm{O}_{4}$ in the meteorite NWA470 by EBSD. The EBSD patterns of the new mineral matched only the highpressure polymorph of $\mathrm{CaAl}_{2} \mathrm{O}_{4}$ rather than that from low-pressure $\mathrm{CaAl}_{2} \mathrm{O}_{4}$.

The binary system of $\mathrm{CaO}-\mathrm{Al}_{2} \mathrm{O}_{3}$ includes two important minerals found in meteorites: hibonite $\left(\mathrm{CaAl}_{12} \mathrm{O}_{19}\right)$ and grossite $\left(\mathrm{CaAl}_{4} \mathrm{O}_{7}\right)$. The discovery of dmitryivanovite presents us with the third calcium aluminum oxide to be described from nature. The most likely scenario for producing dmitryivanovite involves either nebular condensation or evaporation, or a combination of both. Calculations by a diversity of investigators suggest that the condensation of $\mathrm{CaAl}_{2} \mathrm{O}_{4}$ from a nebular system requires considerable enrichment in dust relative to gas [7]. Therefore, the presence of $\mathrm{CaAl}_{2} \mathrm{O}_{4}$ in this $\mathrm{CH} 3$ chondrite suggests that there was just such a region in the solar nebula where dust was suitably abundant. The EBSD analysis in this study reveals that $\mathrm{CaAl}_{2} \mathrm{O}_{4}$ in NWA470 is a high-pressure polymorph.

The phase boundary between low-pressure $\mathrm{CaAl}_{2} \mathrm{O}_{4}$ and the high-pressure polymorph lies from $1 \mathrm{GPa}$ and $700^{\circ} \mathrm{C}$ to $2.5 \mathrm{GPa}$ and $1500^{\circ} \mathrm{C}$ [8]. High pressure ( $\left.2 \mathrm{GPa}\right)$ is required to stabilize the high-pressure $\mathrm{CaAl}_{2} \mathrm{O}_{4}$ polymorph at $1600 \mathrm{~K}$, above which $\mathrm{CaAl}_{2} \mathrm{O}_{4}$ condenses from the solar 
nebula [6]. It is unlikely that the solar nebula ever had such a high total gas pressure, and thus dmitryivanovite probably originally formed with a low-pressure crystal structure. NWA470 shows weakly developed shock features with estimated shock pressure and peak temperatures of $\sim 2 \mathrm{GPa}$ and $<50^{\circ} \mathrm{C}$, respectively [9]. Under these pressure-temperature conditions, the high-pressure polymorph of $\mathrm{CaAl}_{2} \mathrm{O}_{4}$ should be stable because of the large stability field of this phase at low temperatures. Therefore, we believe that the high-pressure polymorph of $\mathrm{CaAl}_{2} \mathrm{O}_{4}$ (dmitryivanovite) was produced during shock metamorphism of the NWA470 parent asteroid.

Andreyivanovite (ideally $\mathrm{FeCrP}$ ) is a new phosphide species from the Kaidun meteorite, which fell in South Yemen in 1980 [10]. Kaidun is a unique breccia containing an unprecedented variety of fragments of different chondritic as well as achondritic lithologies. Andreyivanovite was found as individual grains and linear arrays of grains with a maximum dimension of $8 \mu \mathrm{m}$ within two masses of Fe-rich serpentine. In one sample it is associated with $\mathrm{Fe}-\mathrm{Ni}-\mathrm{Cr}$ sulfides and florenskyite (FeTiP). The average of nine electron microprobe analyses yielded the formula $\mathrm{Fe}\left(\mathrm{Cr}_{0.587} \mathrm{Fe}_{0.150} \mathrm{~V}_{0.109} \mathrm{Ti}_{0.081}\right.$ $\left.\mathrm{Ni}_{0.060} \mathrm{Co}_{0.002}\right) \mathrm{P}$. Examination of single grains of andreyivanovite using Laue patterns collected by in-situ SXRD, and more definitively by EBSD revealed that it is isostructural with florenskyite. Andreyivanovite could have formed as a result of cooling and crystallization of a melted precursor consisting mainly of $\mathrm{Fe}-\mathrm{Ni}$ metal enriched in $\mathrm{P}$, $\mathrm{Ti}$, and $\mathrm{Cr}$. Serpentine associated with andreyivanovite would then have formed during aqueous alteration on the parent asteroid. It is also possible that the andreyivanovite could have formed during aqueous alteration, however, artificial FeTiP has been synthesized only during melting experiments, at low oxygen fugacity, and there is no evidence that a hydrothermal genesis is reasonable.

Aid to Synchrotron X-ray diffraction Studies. In the past decade our groups have made numerous attempts to determine the crystal structures of chondrite sulfides by SXRD, but with only a few exceptions we have found them to be apparently amorphous by this technique. This has always been rather perplexing since these sulfides frequently exhibit euhedral crystal morphologies. We were beginning to conclude that the chondrite sulfides had generally been rendered amorphous by shock. However, we have learned that practically all of our chondrite thin sections have very thin amorphous surfaces, a common polishing side effect of which we were unaware. We have learned that use of a Vibramet polisher can remove this coating, finally permitting elucidation of the crystal structure by EBSD and SXRD. We tested this idea by reanalyzing (by EBSD and SXRD) previously "amorphous" sulfides in the Orgueil and Kaidun meteorites following Vibramet polishing. In both chondrites we have found abundant very crystalline sulfides. We now routinely use EBSD to identify the most well-crystalline sulfides in meteorite samples before taking the much more onerous step of performing SXRD - a fantastic savings in beam time.

\section{References}

[1] Jenniskens et al. (2009) Nature 458, 485-488.

[2] Zolensky et al. Submitted to Meteoritics and Planetary Science.

[3] Takeda et al. (2009) Meteoritics and Planetary Science 44, 5117.

[4] Tribaudino (2006) Meteoritics and Planetary Science 41, 979-988.

[5] Mikouchi et al., (2009) American Mineralogist 94, 746-750.

[6] Ivanova et al. (2002) Meteoritics and Planetary Science 37, 1337-1345.

[7] Ebel and Grossman (2000) Geochimica et Cosmochimica Acta 64, 339-366.

[8] Ito et al. (1980) Materials Research Bulletin 15, 925-932.

[9] Stöffler et al. (1991) Geochimica et Cosmochimica Acta 55, 3845-3867.

[10] Zolensky et al. (2008) American Mineralogist 93, 1295-1299. 